\title{
Análise da aplicabilidade do custeio-meta na etapa de concepção de empreendimentos habitacionais de interesse social
}

\author{
An analysis of the applicability of target costing in the \\ conceptual design phase of low-income housing projects
}

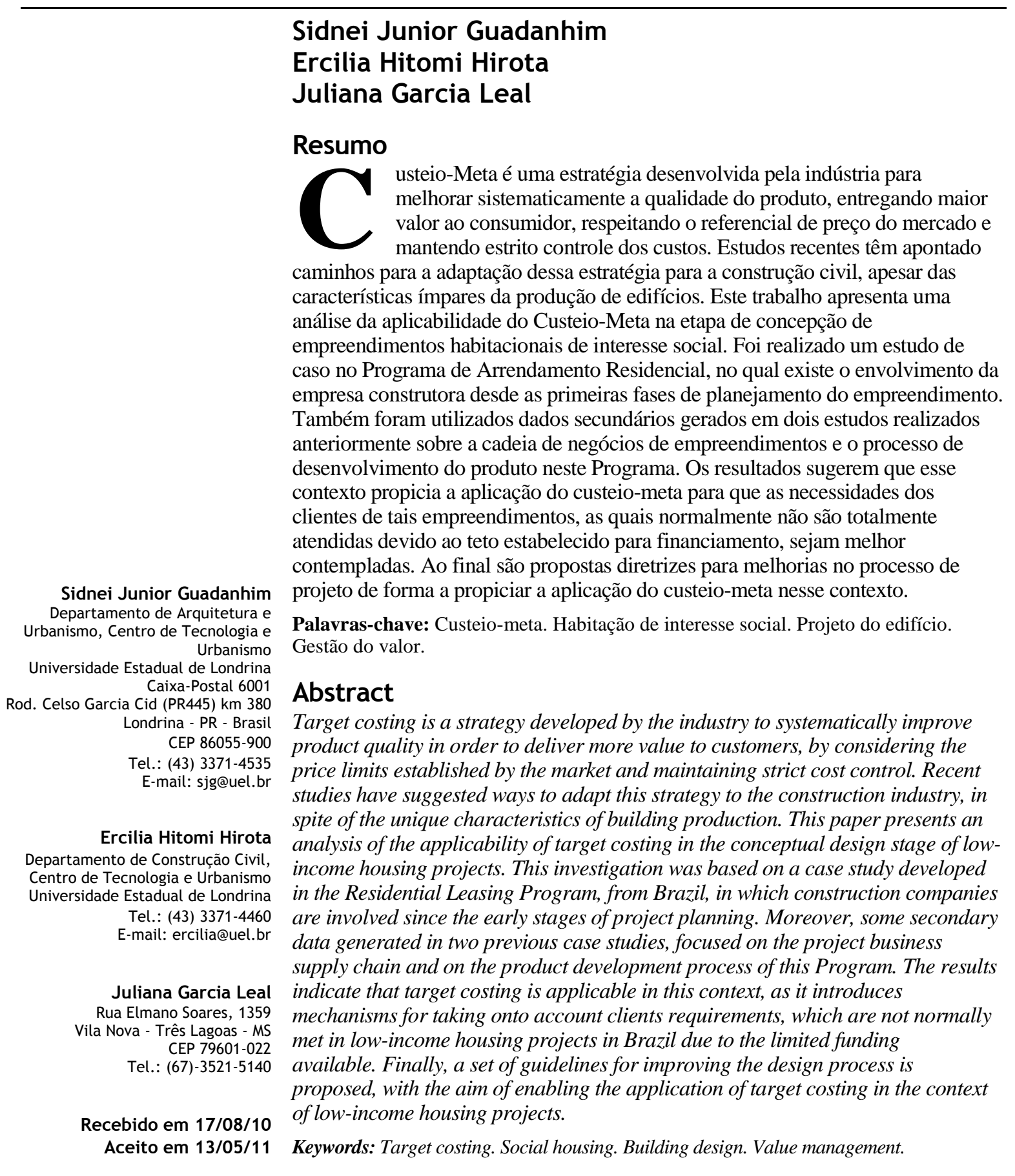

Ambiente Construído, Porto Alegre, v. 11, n. 2, p. 39-56, abr./jun. 2011.

ISSN 1678-8621 @ 2005, Associação Nacional de Tecnologia do Ambiente Construído. Todos os direitos reservados. 


\section{Introdução}

A motivação inicial para a pesquisa que deu origem a este artigo foi a preocupação com o fato de que os custos de um edifício são determinados nos primeiros momentos de sua concepção, ainda na fase de definição do partido arquitetônico. $\mathrm{Na}$ prática, no entanto, aprofundamentos sistemáticos sobre o custo ocorrem tardiamente no processo de desenvolvimento do produto, quando do envolvimento efetivo da equipe de orçamento. Segundo Limmer (1997), o ciclo de vida de um empreendimento compõe-se de quatro estágios básicos: concepção, planejamento, execução e finalização. Nas fases iniciais de desenvolvimento do projeto, embora o grau de incerteza seja grande, as decisões tomadas determinam aproximadamente $85 \%$ do custo final do produto. Alterações sempre ocorrem, mas é importante que elas sejam realizadas no início do desenvolvimento, quando o custo das alterações é menor (AMARAL et al., 2006).

Tradicionalmente, após as definições iniciais de implantação do projeto, a fase de concepção caracteriza-se pela etapa de verificação das viabilidades técnica e econômica. Para tanto, utiliza-se um plano preliminar de implantação, um projeto preliminar de arquitetura, estimativa de custos e cronograma preliminares, possíveis condições de financiamento, identificação das diversas soluções para o programa de necessidades, apresentação daquelas de maior atratividade para apreciação do cliente e definição da alternativa a ser adotada, finalizando com a obtenção da aprovação e da autorização para prosseguir na implementação do projeto (LIMMER, 1997).

Essa sequência, contudo, é bastante arriscada, pois, além de se basear em estimativas de custo, sujeitas a incertezas e variabilidades decorrentes do caráter preliminar das decisões, parte-se do princípio de que os custos são decorrentes da definição do produto e não se cogita a possibilidade de inserir esses custos como variáveis de seu processo de desenvolvimento. Por outro lado, segundo Mascaró (2004), o arquiteto não controla o custo de suas decisões de projeto, porque, em última análise, desconhece suas inter-relações e sua influência no custo final, ficando impossibilitado de comparar, de forma simples e com alguma precisão, os custos de duas alternativas de projeto. Essa comparação só seria possível a partir da obtenção de orçamentos completos dos dois projetos, o que pressupõe a existência de projetos completos. A análise comparativa torna-se, portanto, trabalhosa e inviável (MASCARÓ, 2004).
Os reflexos das decisões arquitetônicas nos custos de empreendimentos destinados à população de baixa renda são ainda mais importantes, na medida em que esses projetos são executados em grande escala e os recursos destinados a sua produção são insuficientes para atender à demanda. $\mathrm{O}$ uso do Custeio-Meta como estratégia para o desenvolvimento desses produtos poderia resultar em maior agregação de valor às habitações, mesmo diante das limitações de recursos. Nessa estratégia, o processo de desenvolvimento do produto não ocorre de modo tão linear, pois, desde o início, os custos estão no centro das preocupações, obrigando a equipe de concepção do produto a efetuar ajustes tão cedo quanto possível.

Nesse sentido, o objetivo do estudo apresentado neste artigo foi analisar a aplicabilidade do Custeio-Meta no processo de desenvolvimento de habitações de interesse social, especificamente no Programa de Arrendamento Residencial (PAR), que reunia as condições favoráveis à aplicação do Custeio-Meta, tais como perfil do cliente bem definido dentro do processo, envolvimento de agentes financiadores, executores e promotores em todo o processo de desenvolvimento do produto, e definição dos projetos, administração e construção das obras a cargo de construtoras, as quais possuem interesse financeiro no projeto. Além disso, a existência de dados em abundância sobre satisfação do cliente voltado à habitação social favorece a implementação dessa estratégia, gerando oportunidades para o desenvolvimento de produtos estritamente voltados para esse públicoalvo. Embora tenha havido uma redução de empreendimentos financiados pelo PAR, justificase a análise apresentada pelas semelhanças com o programa Minha Casa, Minha Vida, implantado em 2009 pelo Governo Federal.

Este trabalho caracteriza-se como um estudo de caso no PAR, com base na análise de dados secundários gerados em estudos realizados anteriormente sobre o processo de desenvolvimento de empreendimentos nesse Programa. Foram examinados o mapa da cadeia de negócios de empreendimentos PAR desenvolvidos em um município brasileiro de médio porte (cerca de 500 mil habitantes), localizado na região Sul do país (SIMÕES; GOMES; HIROTA, 2007), bem como o mapeamento do Processo de Desenvolvimento do Produto (PDP) do PAR nessa mesma localidade (GOMES; GUADANHIM; HIROTA, 2006). A partir dessa análise, esse artigo discute diretrizes para o processo de projeto que propiciem o uso do Custeio-Meta nesse contexto. 


\section{Fundamentação teórica}

Em ambientes competitivos, a sobrevivência de uma empresa depende de dois fatores inseparáveis: a aceitação de seu produto pelo mercado e a geração de lucro. Em termos simples, o lucro resulta da diferença entre o preço de mercado e o custo de produção (MONDEN, 1999).

Assim, enquanto o preço final do produto vendido deve estar em consonância com a realidade do mercado-alvo, o custo de produção deve permitir o alcance de tal preço, garantindo a margem de lucros necessária. Quanto maior a oferta de produtos concorrentes no mercado, maior deve ser a capacidade da empresa em oferecer, pelo mesmo preço final, mais qualidade - ou maior valor agregado. É fácil concluir, portanto, que não basta reduzir o preço final à custa da qualidade, suprimindo ou simplificando itens. Ao contrário, persegue-se o maior valor pelo menor custo, o que exige a máxima eficiência. Por outro lado, a capacidade de identificar em um produto elementos ou funções que não agregam valor ao consumidor pode indicar as frentes a serem atacadas para a redução de custos (SAKURAI, 1989).

Como resposta ao encarecimento das matériasprimas ainda na Segunda Guerra Mundial, a Engenharia de Valor passou a ser aplicada na fase de concepção do projeto, visando reduzir os custos sem prejudicar a qualidade de um produto ou serviço. Ansari (1997) a definem como um método sistemático de avaliar as funções de um produto para determinar se eles podem ser produzidos a um menor custo sem sacrificar desempenho, confiabilidade, utilidade e capacidade de reciclagem do produto. Segundo Cooper e Slagmulder (1997), a Engenharia de Valor possui dois conceitos fundamentais: função e valor. $\mathrm{O}$ valor representa a melhor combinação entre custo e desempenho, e pode ser expressa numa equação Valor = Função/Custo, ou seja, quanto maior a função, neste caso o desempenho de um produto ou serviço, e menor seu custo, maior será seu valor agregado. Assim, a Engenharia de Valor consiste em assegurar o desempenho da função de um produto ou serviço ao menor custo possível, sem que a função seja prejudicada (GRANJA; PICCHI; ROBERT, 2005).

Ao longo dos últimos 30 anos, empresas japonesas têm desenvolvido estratégias de gerenciamento do lucro, a partir dos princípios da Engenharia de Valor. Uma dessas estratégias é conhecida como Custeio-Meta ou Target Costing, definida por
Ansari, Bell e Target Cost Core Group (1997 ${ }^{1}$ apud NICOLINI et al., 2000) como um "sistema de planejamento de lucros e custos" focado no preço, no cliente, no projeto e na funcionalidade, cuja principal característica é sua aplicação desde as primeiras fases de concepção de um produto.

Desse ponto de vista, o processo de desenvolvimento do produto passa, necessariamente, por um estrito estudo para determinação do custo-alvo, o qual se baseia em dados referenciais do mercado e no profundo conhecimento do produto desejado, de modo que seja possível atribuir custos a suas funções e componentes. Para Gaiser (1997), o conceito de Custeio-Meta envolve os mesmos componentes do custeio tradicional: custo do produto, lucro e preço final. No entanto, o Custeio-Meta centra-se no preço que o consumidor está disposto a pagar, determina-se uma margem aceitável de lucro e trabalha-se no sentido contrário, buscando um custo aceitável. Em termos simples, mais recursos serão investidos nos atributos que são mais valorizados pelo cliente final. Essa estratégia é, portanto, orientada ao mercado, ou seja, nas expectativas do consumidor e em sua disposição de pagamento.

Há diferentes enfoques para a definição do conceito de Custeio-Meta ${ }^{2}$, Cokins (2002) define Custeio-Meta como uma técnica de modelagem de custos que identifica qual preço os consumidores estão dispostos a pagar por determinado produto, para daí determinar as margens de lucro e custos permissíveis, sendo aplicado no início do ciclo de vida do produto, durante a fase de conceituação e design. Na mesma linha, Monden (1999) define Custeio-Meta como um sistema que incorpora a administração do lucro durante a etapa de desenvolvimento do produto, que, de modo geral, precisa atingir os objetivos de:

(a) reduzir os custos de novos produtos, garantindo o lucro requerido e satisfazendo os níveis de qualidade exigidos pelo mercado; e

(b) motivar toda a cadeia a alcançar o lucro-alvo durante o desenvolvimento de novos produtos, tornando o custo-alvo uma atividade de administração do lucro. Ansari (1997) denominam Target Costing como um sistema de planejamento de lucros e custos.

\footnotetext{
${ }^{1}$ ANSARI, S.; BELL, J.; CAM-I TARGET COST CORE GROUP. Target Costing: the next frontier in strategic cost management. Chicago: Irwin, 1997.

${ }^{2}$ Tais definições também são apresentadas em Granja et al. 0 Custeio-Meta para o Desenvolvimento de Habitações de Interesse Social: diretrizes a partir da comparação de duas modalidades de provisão. Trabalho desenvolvido paralelamente pelos autores.
} 
Por outro lado, Nicolini et al. (2000) definem Custeio-Meta como uma estratégia para o desenvolvimento de novos produtos que envolve todos os agentes do processo, objetivando a redução dos custos ao longo da vida, enquanto assegura qualidade, confiabilidade e demais requisitos do cliente. Para tanto, são examinadas todas as ideias possíveis durante os estágios de planejamento, pesquisa e prototipagem, na qual o domínio pleno dos custos deve ocorrer desde as primeiras fases de concepção (pré-design) e acompanhar o PDP até a produção. É esse o conceito adotado pelos autores do presente artigo.

Cooper e Slagmulder (1997) argumentam que o Custeio-Meta é mais do que uma técnica ou ferramenta de gestão de custos e lucros. Também o concebem como uma estratégia de desenvolvimento de produtos (COOPER; SLAGMULDER, 1997), na qual o custo de produção é convertido de uma consequência do projeto para um parâmetro do projeto (IBUSUKI; KAMINSKY, 2007; BALLARD; REISER, 2004), como forma de manter a empresa na "zona de sobrevivência", uma faixa na qual o produto mantém-se competitivo no mercado.

Segundo Cooper e Slagmulder (1997), o cerne do Custeio-Meta reside na ideia simples de que custoalvo equivale à subtração do lucro-alvo do preçoalvo. Contudo, essa simplicidade esconde um rico e complexo processo desenvolvido pelas empresas japonesas, o qual, embora possa variar consideravelmente, possui estrutura básica composta de três principais partes: custeio baseado no mercado, custeio em nível do produto e custeio em nível do componente. O custeio baseado no mercado é usado para estabelecer o custo permissível do produto, ou custo competitivo. O custeio em nível de produto estabelece o custo- alvo do produto, com o emprego de Engenharia de Valor. Por último, custeio em nível do componente é usado para estabelecer o custo-alvo dos componentes do produto, o que envolve, necessariamente, a cadeia de suprimentos. Esperase que os fornecedores encontrem meios para que os componentes mantenham a qualidade dentro do custo-alvo estabelecido, o que implica envolvimento e ações cooperativas (COOPER; SLAGMULDER, 1997).

Cooper e Slagmulder (1997) enumeram e exemplificam situações em que há fatores que influenciam positiva ou negativamente a aplicação de Custeio-Meta, dependendo das características de cada empresa ou setor. Não há um cenário ideal aplicável genericamente a todos os casos. Ao contrário, um fator pode ser positivo para a empresa A, enquanto pode ser desfavorável para a empresa B, como demonstrado nos estudos realizados em diversas empresas japonesas. A Figura 1, portanto, pode ser útil se levadas em consideração todas as variáveis de determinada empresa ou setor.

Evidentemente, há uma série de dificuldades para a implantação da estratégia Custeio-Meta. Sua real capacidade deve ser compreendida claramente pelos envolvidos: gestores devem tomar decisões tendo clara compreensão da dinâmica de custos da empresa ou organização; decisões devem saltar do nível do produto para o nível da organização, como forma de eliminar inconsistências resultantes de problemas encontrados com custos; e, finalmente, as ações devem basear-se em informações sólidas e nas reais capacidades da empresa (YU-LEE, 2002). Notoriamente, os custos do produto são difíceis de determinar ou gerenciar, mesmo contando com a mais completa informação.

\begin{tabular}{|c|c|c|}
\hline \multicolumn{2}{|c|}{ Custeio-Meta - Processo } & $\begin{array}{l}\text { Fatores que influenciam positiva ou negativamente a aplicação de } \\
\text { Custeio-Meta, dependendo das características de cada empresa }\end{array}$ \\
\hline \multirow{4}{*}{$\begin{array}{l}\text { CUSTEIO } \\
\text { BASEADO NO } \\
\text { MERCADO }\end{array}$} & \multirow{4}{*}{$\begin{array}{l}\text { Natureza do } \\
\text { Consumidor }\end{array}$} & Intensidade de competição \\
\hline & & Grau de sofisticação do cliente \\
\hline & & Frequência com que as exigências dos clientes mudam \\
\hline & & Grau de entendimento sobre os requisitos futuros do produto \\
\hline \multirow{6}{*}{$\begin{array}{l}\text { CUSTEIO } \\
\text { NÍVEL DO } \\
\text { PRODUTO }\end{array}$} & \multirow{3}{*}{$\begin{array}{l}\text { Estratégia do } \\
\text { Produto }\end{array}$} & Variedade de produtos sendo produzidos \\
\hline & & Frequência de lançamentos de modelos revisados/atualizados \\
\hline & & Grau de inovação do produto \\
\hline & \multirow{3}{*}{$\begin{array}{l}\text { Características } \\
\text { do Produto }\end{array}$} & Complexidade do produto \\
\hline & & Investimento inicial necessário para se produzir \\
\hline & & Duração da fase de desenvolvimento de produto \\
\hline \multirow{3}{*}{$\begin{array}{l}\text { CUSTEIO - } \\
\text { NÍVEL DO } \\
\text { COMPONENTE }\end{array}$} & \multirow{3}{*}{$\begin{array}{l}\text { Estratégia da } \\
\text { Cadeia de } \\
\text { Suprimentos }\end{array}$} & Grau de integração horizontal (número de produtos/serviços terceirizados) \\
\hline & & Influência sobre os fornecedores \\
\hline & & Relação entre produtor (comprador) e sua cadeia de suprimentos \\
\hline
\end{tabular}

Figura 1 - Fatores que influenciam a aplicação de Custeio-Meta

Fonte: adaptado de Cooper e Slagmulder (1997). 


\section{Custeio-Meta aplicado à construção civil}

No Brasil, embora sejam perceptíveis os esforços dedicados ao aumento da produtividade e qualidade, os maiores avanços obtidos no setor da construção civil ocorreram no canteiro de obras, com o uso de novas tecnologias e a adoção de sistemas de qualidade (REIS; PICCHI, 2003). Menos atenção tem sido dedicada às atividades relacionadas à concepção e ao desenvolvimento do produto, apesar do considerável impacto em qualidade, custo e prazo.

Jacomit e Granja (2008) apontam pesquisas recentes com indicações favoráveis à ideia de implantação de Custeio-Meta na construção civil, incluindo o dado de que empresas construtoras japonesas já o têm implantado, obtendo resultados positivos (YOOK; KIM; YOSHIKAWA, $2005^{3}$ apud JACOMIT; GRANJA, 2008). Em seguida, analisam três casos nos quais a aplicação de Custeio-Meta ocorreu de modo parcial.

O primeiro, apresentado por Nicolini et al. (2000), trata de instalações militares no Reino Unido cujo custo-meta foi obtido de dados históricos e incluiu o processo de projeto. Porém, os autores concluíram que a aplicação de Custeio-Meta não era viável, principalmente devido a particularidades da indústria da construção naquele país, a qual, via de regra, não utiliza as mais avançadas técnicas construtivas, como, por exemplo, componentes padronizados. Falta integração entre diferentes especialidades assim como são comuns os problemas de integração de projetos e obra. O segundo caso, conforme Ballard e Reiser (2004), um ginásio de esportes em uma universidade norte-americana, teve o custo-meta estabelecido não com base no mercado, mas em função da verba disponibilizada por meio de uma doação. O processo de projeto foi parte integrante da estratégia, mas a equipe foi formada após os esquemas iniciais terem sido definidos, ou seja, as fases iniciais (pré-projeto) não ocorreram sob a abordagem do Custeio-Meta. Mesmo assim, a conclusão dos autores foi favorável à aplicabilidade. Por último, Robert e Granja (2006) publicam o caso de uma rede de unidades de varejo no Brasil cujo custo-meta havia sido estabelecido com base em dados históricos de obras da rede. Embora não tenha incluído o processo de projeto - o que aproxima o estudo do

${ }^{3}$ YOOK, K.; KIM, I.; YOSHIKAWA, T. Target Costing in the Construction Industry: evidence from Japan. Construction Accounting \& Taxation, v. 15, n. 3, p. 5-18, may/jun. 2005. kaizen costing ${ }^{4}$ - os resultados obtidos em redução de custo, mantendo a qualidade com foco nos requisitos dos clientes, também aponta favoravelmente à aplicação de Custeio-Meta na construção civil.

Ballard (2006) defende a integração do CusteioMeta nas fases iniciais de concepção. Propõe, dentro do que define como Lean Project Delivery System, sua inserção na fase de definição de projeto (project definition), uma etapa inicial, anterior ao desenvolvimento propriamente dito do projeto do produto, que ocorre de modo cíclico, envolvendo três elementos primários: os objetivos do cliente ou empreendedor, os meios para se atingir estes objetivos, ou seja, conceitos de projeto e, por fim, as restrições ou condicionantes do processo. As características iniciais de concepção do produto, embora de difícil descrição, são apontadas há décadas por diversos autores, mesmo que com diferentes denominações. ${ }^{5} \mathrm{~A}$ introdução do Custeio-Meta neste momento do PDP é um aspecto fundamental, ou seja, quando os problemas de projeto são gerados e compreendidos.

Num cenário ideal, o custo-meta, tanto do produto como dos componentes, já precisa ser considerado desde o início. Naturalmente, isso não pode ser feito se o processo recair apenas sobre um dos agentes. É necessário, desde a etapa de definição do projeto, o envolvimento pleno, inclusive de agentes externos. Ballard (2006) observa a possibilidade de times multidisciplinares explicitarem metas de custos, com troca de informações com relação aos elementos primários que afetam os custos do produto, e destaca a participação da cadeia de fornecedores junto a essa equipe para que tais metas sejam atingidas, ou seja, os estudos de viabilidade e concepção de projetos devem ser realizados com o envolvimento de todos os agentes do processo. Entretanto, essa não é a prática observada. É comum que a concepção do produto ocorra sem a devida integração e comprometimento de todos os projetistas e demais agentes com o cliente financiador do projeto. Ballard (2006) ressalta que esses times são constituídos tardiamente, somente depois de concluído o estudo de viabilidade.

Cada edifício é concebido e projetado para um cliente único e específico, o que torna a introdução

\footnotetext{
${ }^{4}$ Processo de redução de custos durante a fase de produção. 0 termo japonês kaizen significa "melhorias em pequenos passos", ou seja, melhoria contínua (MONDEN, 1999).

${ }^{5} \mathrm{Com}$ respeito ao processo de projeto em arquitetura e suas fases, desde a década de 1960 há diversas contribuições, algumas das quais são citadas em: MCGINTY, T. Projeto e Processo de Projeto. In: SNYDER, J.; CATANESE, A. Introdução à Arquitetura. Rio de Janeiro: Campus, 1984. p. 160-194.
} 
da estratégia Custeio-Meta na construção civil um objeto de pesquisa desafiador (BALLARD, 2006). Nos casos estudados por Jacomit e Granja (2008), Nicolini et al. (2000) e Ballard (2006) não houve uma aplicação plena de todas as premissas teóricas e recomendações oriundas da indústria manufatureira:

(a) em especial, a premissa do preço estabelecido pelo mercado não foi testada;

(b) o envolvimento da cadeia ocorre parcialmente;

(c) os fornecedores de materiais de construção em geral são maiores do que as empresas construtoras, limitando a margem de negociação e o pleno envolvimento dos fornecedores no processo desde o início; e

(d) é quase impossível trabalhar com o custo ao longo da vida do produto, que neste caso é um edifício.

Com base na revisão de literatura, um cenário hipoteticamente indicado para a aplicação de Custeio-Meta contemplaria, resumidamente, os seguintes princípios:

(a) consideração do mercado, seu ambiente competitivo e os requisitos do cliente como referências básicas para todo o processo;

(b) gestão eficiente de informações e custos, bem como o domínio dos custos, e não dos preços dos componentes e serviços, e do custo ao longo da vida útil do produto;

(c) avaliação contínua, pois o processo é cíclico, não linear;

(d) utilização combinada de técnicas de Engenharia de Valor, associadas à criatividade da equipe de projeto, à formação de equipes multidisciplinares e à estruturação dos custos baseada em funções, de modo a permitir a avaliação do valor agregado e percebido pelo usuário; e

(e) envolvimento de toda a cadeia do PDP (investidores, projetistas, fornecedores, construtores, vendedores e clientes), com a formação de equipes multidisciplinares e a implementação de peças e componentes modulares ou padronizados.

$\mathrm{Na}$ pesquisa apresentada neste artigo foi analisado o caso específico da produção de empreendimentos de habitação de interesse social (EHIS), já que é possível identificar algumas características favoráveis:

(a) a pressão externa da concorrência, prevista na teoria, pode equivaler às condições impostas pelos órgãos financiadores; (b) o custo-meta extraído do mercado já existe, através dos dados das companhias de habitação, que conhecem o usuário final, sua capacidade de endividamento e suas exigências e os limites de financiamento dos Programas;

(c) a produção em série de habitações aproxima esse tipo de edifício da manufatura, berço do Custeio-Meta; e

(d) o padrão de exigência dos usuários é crescente, o que obriga as empresas a entregarem mais valor sem aumentar o preço final.

Para que o Custeio-Meta seja aplicado de maneira eficaz, é necessário o estabelecimento de uma organização baseada em equipes multidisciplinares (marketing, engenharias, produção, compras e financeiro), de forma a haver geração de ideias e análise de alternativas. Segundo Jacomit e Granja (2008), no desenvolvimento de produtos na construção civil, essa equipe deve ser formada fundamentalmente por pessoas que representem a empresa de projetos arquitetônicos e instalações, a construtora, o cliente, os fornecedores e prestadores de serviços-chave, ou seja, é necessária a implementação de ações de gestão. Nas duas últimas décadas, houve avanços significativos nos estudos sobre gestão do processo de projeto. ${ }^{6}$ Além disso, é necessário o uso de um modelo de custo que dê suporte às decisões de fabricação, para que a empresa possa avaliar adequadamente se terá condições de produzir determinado produto.

\section{Método de pesquisa}

O estudo de caso foi realizado no Programa de Arrendamento Residencial (PAR), cuja característica básica é o envolvimento dos responsáveis pela construção desde as primeiras fases de planejamento do empreendimento, e envolveu a análise de dados secundários gerados em dois estudos realizados anteriormente, em um município de médio porte (cerca de 500 mil habitantes), localizado na região Sul do país, sobre a cadeia de negócios de empreendimentos e o Processo de Desenvolvimento do Produto (PDP) do PAR.

O primeiro estudo (GOMES; GUADANHIM; HIROTA, 2006) resultou no mapeamento do PDP do PAR desenvolvido pela companhia de

\footnotetext{
${ }^{6}$ Melhado (1997) destaca um conjunto de ações de gestão: definição de critérios para qualificação de projetistas; contratação de consultores; desenvolvimento de uma contratação de consultores; desenvolvimento de uma
metodologia de projeto (definição do fluxo de atividades necessárias e dos procedimentos de coordenação e controle); padronização e atualização de procedimentos de execução e controle dos serviços de produção; gerenciamento da execução a partir dos subsídios fornecidos pelos procedimentos de execução e controle e pelos projetos para produção; e coleta e análise de dados para a retroalimentação do projeto.
} 
habitação local, a partir das diretrizes propostas por Miron e Formoso (2003) para gestão de requisitos de cliente, consistindo nas etapas de identificação dos principais clientes, identificação dos requisitos dos clientes, identificação dos tomadores de decisão e formalização das relações cliente-fornecedor (mapa). Os dados foram coletados por meio de entrevistas semiestruturadas e análise de documentos.

O outro estudo, desenvolvido por Simões, Gomes e Hirota (2007), resultou em um mapa da cadeia de negócios de empreendimentos PAR nos quais a companhia de habitação local atuava como um dos agentes da cadeia. Esse estudo partiu de uma análise documental que envolveu a legislação e a regulamentação do Programa, no sentido de compreender o processo de desenvolvimento de empreendimentos e de identificar oportunidades e riscos presentes nesse negócio. Posteriormente foram coletadas informações adicionais para detalhamento do processo na companhia de habitação, por meio de uma série de três entrevistas com o diretor técnico, responsável pelo Programa. A ferramenta adotada para a realização dessas entrevistas foi o mapa de fluxo de processo, no qual os dados coletados foram organizados. A cada entrevista o mapa era reformulado, acrescentando-se as informações colhidas, até a versão final, considerada fidedigna pelo diretor técnico.

A revisão de literatura sobre Custeio-Meta permitiu identificar condições necessárias, bem como fatores que favorecem ou desfavorecem a aplicação dessa estratégia. Esses fatores ou condições constituíram o conjunto de construtos adotados na análise dos resultados dos dois estudos mencionados, que estão apresentados nos itens de $i$ a $v$, ao final da fundamentação teórica deste artigo.

A partir da discussão desses fatores, foram feitas considerações acerca do desenvolvimento da etapa de pré-projeto dos empreendimentos PAR, com base na revisão de literatura, e apresentadas diretrizes para o processo de projeto que propiciem o uso do Custeio-Meta nesse contexto.

\section{Caso estudado: PAR}

O PAR, criado em 2001, é um dos programas habitacionais criados pelo Ministério das Cidades, visando atender o déficit habitacional urbano das capitais estaduais, regiões metropolitanas e municípios com população urbana superior a cem mil habitantes. Foi desenvolvido para atender famílias com renda de até $\mathrm{R} \$$ 1.800,00, objetivando a promoção e a realização de empreendimentos a um custo que se viabilize tanto pelo aspecto da rentabilidade e lucros proporcionados ao empreendedor quanto pela possibilidade de pagamento por parte do públicoalvo.

O programa consiste na construção e arrendamento de unidades residenciais, com opção de compra do imóvel ao final do período contratado, de 15 anos. Objetiva a aquisição de imóveis a serem construídos, em construção e para recuperação. O número máximo de unidades habitacionais para aprovação por empreendimento é de 500 unidades, sendo a área mínima da unidade padrão $37 \mathrm{~m}^{2}$. O prazo de execução das obras é limitado a, no máximo, 18 meses, contados da data da assinatura do contrato.

O Processo de Desenvolvimento de Produto (PDP) engloba todas as fases, agentes e especialidades de interesse referentes ao produto, no qual são consideradas as informações do mercado, dos diversos projetistas, das equipes de produção, bem como testes e análises de uso do produto como fontes para a formulação de requisitos, definições, detalhamentos e aperfeiçoamentos do projeto desse produto (AMARAL et al., 2006). Engloba, portanto, o desenvolvimento completo de um produto, desde a concepção e desenvolvimento dos projetos, bem como sua produção e uso. Segundo Gomes, Guadanhim e Hirota (2006), um dos maiores problemas do PDP na construção civil é a falta de integração harmônica entre os vários processos que o compõem, principalmente entre os processos de projeto e construção.

O mapeamento do PDP do PAR proposto por Gomes, Guadanhim e Hirota (2006) mostra que a etapa de pré-projeto dos empreendimentos, na qual são definidas as diretrizes gerais e estabelecidos critérios delimitadores das características do empreendimento, tem a participação de um grande número de agentes (Figura 2). O Ministério das Cidades (MinCidades) e a Caixa Econômica Federal (CAIXA) são os principais balizadores desse processo, segundo Gomes, Guadanhim e Hirota (2006) muitas das restrições observadas no estudo desenvolvido tiveram origem nas determinações da CAIXA, nessa etapa. A empresa construtora participa dessa etapa como proponente e responsável pelo desenvolvimento do empreendimento. A companhia de habitação é responsável pela coleta de informações a respeito da demanda, as quais são fornecidas aos projetistas e tomadores de decisão. No caso estudado, a companhia era responsável, também, pela definição do terreno no qual o empreendimento seria executado. A imobiliária tinha um papel secundário na etapa de pré-projeto do caso estudado: assinava o convênio, porém não interferia no delineamento do empreendimento, embora pudesse contribuir com as informações 
relacionadas ao uso e ocupação de empreendimentos já existentes. O instituto de planejamento urbano do município e o Ministério das Cidades têm participação como reguladores: o primeiro com relação ao uso e ocupação do solo, e o segundo com relação ao Programa. Por fim, o usuário final participa da etapa de pré-projeto, de forma indireta, por meio do fornecimento de informações à companhia de habitação, por ocasião da inscrição como interessado na aquisição da casa própria.

Sob a perspectiva da estratégia de Custeio-Meta, a fase pré-projeto é fundamental para o sucesso do empreendimento, tanto sob o ponto de vista dos agentes promotores como dos clientes finais. Como o objetivo da fase de pré-projeto é a análise do mercado, além dos dados relativos ao déficit habitacional local e disponibilidade de recursos fornecidos pelo MinCidades e CAIXA para análise de viabilidade, é fundamental que se obtenham informações sobre os requisitos dos usuários a serem atendidos. No mapeamento analisado, os usuários são envolvidos na fase de pré-projeto apenas como fontes e informações cadastrais, para efeito de levantamento de demanda.

Gomes, Guadanhim e Hirota (2006) apontam o caráter burocrático dessa coleta como uma deficiência no PDP analisado e propõem alterações no instrumento de coleta, de forma a se obterem informações relevantes para a captura de requisitos de usuários. Da mesma forma, a participação da imobiliária, empresa contratada para administrar os imóveis em uso, restringe-se ao fornecimento de informações burocráticas para sua contratação quando poderia fornecer informações importantes acerca do perfil de uso e de custos de operação e manutenção das edificações para o desenvolvimento dos projetos.

Observa-se que a estrutura do PDP do PAR poderia permitir a inserção de alterações operacionais, de modo a propiciar uma avaliação mais adequada para maior agregação de valor ao produto EHIS. No entanto, é importante analisar o processo de negócio desse Programa, ou seja, como se estabelecem as relações entre os diferentes agentes desse processo no que se refere aos interesses individuais. Por se tratar de um contexto social e de interesse público, a obtenção de lucro na análise da estratégia de Custeio-Meta deve ser substituída pelo atingimento dos objetivos de cada agente.

Segundo Simões, Gomes e Hirota (2007), a cadeia de negócios se estabelece a partir da interação dos processos de negócio de cada agente no processo de desenvolvimento de um empreendimento PAR. Os principais agentes envolvidos nesse programa (Figura 3) e suas respectivas competências são apresentados a seguir (SIMÕES; GOMES; HIROTA, 2007).

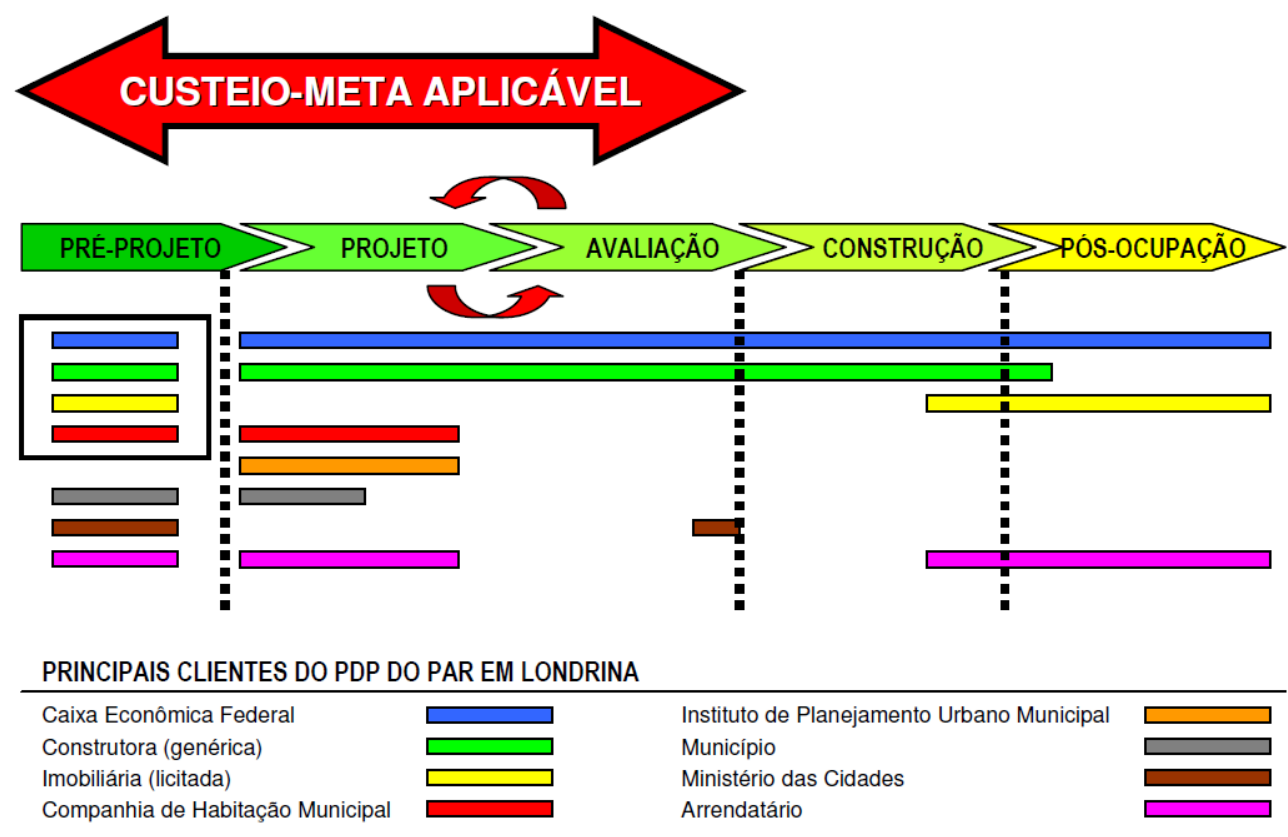

Figura 2 - PDP do PAR e seus agentes

Fonte: adaptado de Gomes, Guadanhim e Hirota (2006). 


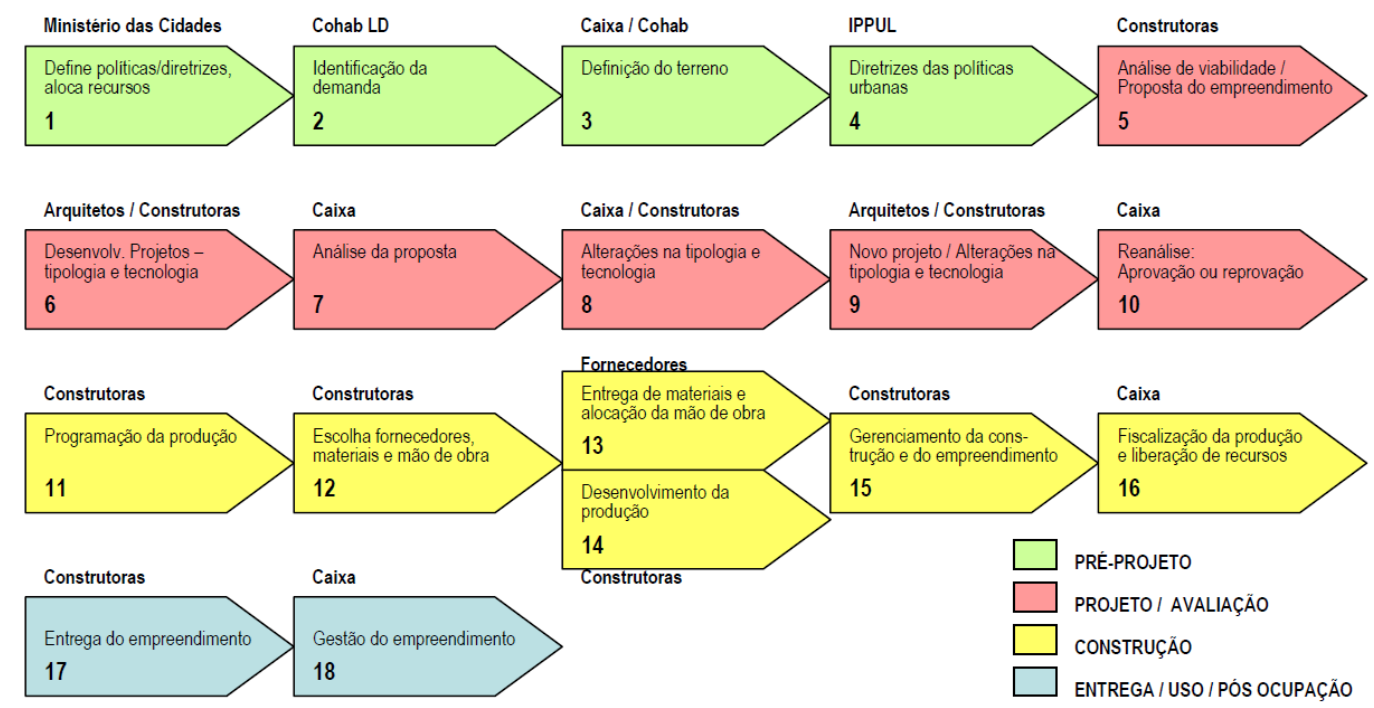

Figura 3 - Processos de negócios do programa PAR

Fonte: adaptado de Simões, Gomes e Hirota (2007).

O MinCidades é o agente gestor do PAR, a quem compete estabelecer diretrizes, fixar regras e condições para implementação do Programa, e alocar os recursos entre as Unidades da Federação. Estabelece as áreas de atuação, público-alvo, valor máximo de aquisição da unidade habitacional objeto de arrendamento e acompanhamento e avaliação do desempenho do Programa, em conformidade com os objetivos estabelecidos por lei.

A CAIXA é o agente financeiro vinculado ao Governo Federal, executor do PAR, responsável pela alocação dos recursos, definição dos critérios e expedição dos regulamentos necessários à operacionalização do Programa. É o grande tomador de decisões, com participação intensa em todas as etapas do processo. Elabora convênios com as prefeituras e convoca oficialmente as construtoras para participar do processo licitatório, aprova os projetos e os fiscaliza, e libera recursos para a construção e compra das unidades.

Os Poderes Públicos Estadual e Municipal têm sua participação estabelecida por meio de assinatura de convênio com a CAIXA, visando assegurar sua colaboração nas ações que favoreçam a implementação dos projetos, destacando-se a indicação das áreas prioritárias para implantação deles, isenção de tributos e indicação de demanda para os empreendimentos. A prefeitura indica as famílias candidatas ao arrendamento. Esse processo é realizado pela companhia de habitação (COHAB) local, mas a seleção dos arrendatários e a escolha das empresas responsáveis pela administração dos imóveis são realizadas pela CAIXA. Atua também em âmbito municipal o instituto de pesquisas e planejamento urbano municipal (IPPUL), respondendo pela aprovação do empreendimento, de acordo com as diretrizes da política de ocupação do solo urbano.

As empresas construtoras participam na apresentação de propostas e execução dos projetos aprovados pelo Município e pela CAIXA. Atuam em conjunto com as construtoras a equipe de projetistas, responsáveis pela realização dos projetos, como arquitetos e engenheiros, e a equipe de fornecedores de materiais, componentes e mão de obra.

O arrendatário ou usuário final é a pessoa física que, atendendo aos requisitos estabelecidos para o Programa, é habilitado pela CAIXA ao arrendamento de imóvel do PAR. As famílias interessadas procuram a COHAB local para se candidatar, a qual faz uma pré-seleção e as indicam para a CAIXA, responsável pela seleção final.

Por fim, as empresas do ramo da administração imobiliária são empresas contratadas para administrar os contratos de arrendamento, os imóveis e também os condomínios, quando se tratar de empreendimentos habitacionais multifamiliares.

Segundo Simões, Gomes e Hirota (2007), a identificação da demanda (processo 2 da Figura 3), realizada pela COHAB local, traz vantagens à cadeia, já que define a demanda em termos da quantidade e qualidade, fazendo com que o projeto seja direcionado ao atendimento da demanda e que haja agilidade no processo de arrendamento das unidades habitacionais. Essas informações são também importantes para que a empresa faça a análise de viabilidade econômico-financeira 
(processo 5) de forma adequada. O incentivo à participação de empresas construtoras qualificadas nessa cadeia é fundamental para o sucesso do PAR. No entanto, a análise do PDP desenvolvida por Gomes, Guadanhim e Hirota (2006) aponta a necessidade de melhoria da qualidade dessas informações, conforme discutido anteriormente.

Os processos 6, 7, 8, 9 e 10, respectivamente desenvolvimento do projeto, análise da proposta, alterações de tipologia e tecnologia, novo projeto e reanálise do projeto, representam um gargalo na definição do produto a ser realizado. A falta de integração entre os agentes envolvidos e o caráter burocrático das análises desenvolvidas pela CAIXA, no caso estudado, dificultam o entendimento comum quanto às características necessárias ao empreendimento, trazendo custos adicionais para o projeto, prazos maiores na realização do empreendimento e menor rentabilidade para o empreendedor, ocasionando redução da oferta de empreendimentos para o mercado.

Novamente observa-se a necessidade de uma atuação mais proativa dos agentes promotores, como na análise do PDP do PAR, no sentido de obter informações que efetivamente contribuam para maior agregação de valor ao produto.

$\mathrm{O}$ aspecto mais relevante, na análise da cadeia de processos de negócios, sob a ótica da estratégia Custeio-Meta, é a participação tardia dos fornecedores de materiais e componentes. Não há participação desses agentes nas etapas de definição do produto. Somente após a aprovação do financiamento, pela CAIXA, a empresa construtora faz o contato com os fornecedores para aquisição dos materiais e componentes.

\section{Discussões}

Um dos requisitos básicos da estratégia CusteioMeta é a composição de uma equipe interdisciplinar, altamente comprometida com os objetivos estabelecidos e que inclua todos os agentes envolvidos, desde o empreendedor - ou o idealizador do empreendimento - até os responsáveis pelo fornecimento de insumos, materiais e componentes que comporão o produto final, passando necessariamente pelas equipes de projeto e execução. Só assim é possível considerar o pleno domínio de todos os custos relacionados, algo ainda distante da realidade da construção civil.

Esse pensamento, segundo a literatura estudada, alinha-se com os objetivos estratégicos das empresas construtoras. $\mathrm{O}$ gestor do empreendimento dá início ao processo do Custeio-
Meta pela apresentação das vendas de longo prazo e os objetivos de lucro da empresa. Para dar suporte a esses objetivos, é estabelecido um planejamento do produto no longo prazo, compreendendo análises detalhadas dos consumidores e tendências competitivas. Para que isso ocorra no contexto de EHIS, os modelos contratuais e as formas de relacionamento entre os envolvidos dentro do processo necessariamente teriam de passar por transformações e adaptações.

Apresenta-se, a seguir, uma análise das características do PAR à luz dos princípios que configurariam um cenário hipoteticamente indicado, de acordo com a revisão bibliográfica apresentada e apoiada pelo fluxograma de processo de desenvolvimento de um EHIS com a aplicação de Custeio-Meta organizado por Jacomit e Granja (2008). Posteriormente, a partir dessa análise, discutem-se diretrizes para o processo de projeto que propiciem a aplicação do Custeio-Meta nesse contexto de desenvolvimento de EHIS em mercado competitivo.

Esta análise parte do pressuposto de que esforços, tempo e recursos destinados ao desenvolvimento avançado de processos, elementos, componentes e serviços voltados à produção de unidades habitacionais, cuja demanda é sabidamente elevada, justificam a investigação: o investimento no planejamento repercute diretamente na economia da obra, tanto em termos de custos como de prazos de execução, agregando mais valor aos clientes.

\section{Análise das características do PAR ante os princípios da aplicação do Custeio- Meta}

\section{Consideração do mercado, seu ambiente competitivo e os requisitos do cliente como referências básicas para todo o processo}

Embora a definição de políticas e diretrizes, a alocação de recursos e a identificação e seleção da demanda dos programas habitacionais, de uma forma geral, sejam feitas pelo Ministério das Cidades, por intermédio da CAIXA, é comum encontrar ofertas similares no mercado para a mesma faixa de renda atendida pelo PAR. Isso significa que o produto do Programa precisa ser competitivo, pois, se de um lado o preço final é estabelecido com base em dados reais de capacidade de endividamento do usuário, por outro deve enquadrar-se na realidade imobiliária local. Além disso, há concorrência, pois a proposição do empreendimento é aberta à iniciativa privada, a qual elabora estudos de viabilidade e projetos, enquadra o produto no preço final (custo-meta) 
preestabelecido pelo Programa e aprova o empreendimento junto à CAIXA. Apenas as propostas mais consistentes e de maior qualidade, com o mesmo orçamento, são aprovadas.

Esse contexto, muito similar ao programa Minha Casa, Minha Vida, é desafiador, na medida em que na faixa de renda mínima (cerca de $\mathrm{R} \$ 1.800,00$ ) as exigências do usuário são maiores do que em programas tradicionais de provisão de HIS. Por exemplo, é comum o usuário exigir vaga de estacionamento, preferencialmente coberta. A complexidade dos requisitos diante do teto estabelecido pelo financiamento requer o uso de um ferramental de desenvolvimento de produto adequado, que propicie o balanceamento entre valor, desempenho e custo. Como consequência, a qualidade da base de informações gerenciais disponíveis passa a ser fundamental. Outros dois princípios da implementação do Custeio-Meta tratam desses aspectos.

\section{Gestão eficiente de informações e custos, bem como o domínio dos custos e não dos preços dos componentes e serviços e do custo ao longo da vida útil do produto}

Como aspectos favoráveis do Programa PAR nesse quesito, podem ser apontados o conhecimento prévio do preço final do produto, estabelecido pelos órgãos governamentais, e a produção em série. Essas duas características tendem a facilitar a coleta e a gestão de informações relacionadas a custos e desempenho do produto, tanto no sentido de retroalimentar a concepção de novos produtos como para efeito de controle de custos de produção.

Mas é preciso reconhecer que as empresas construtoras, com raras exceções, não possuem controle pleno de custos e estrutura adequada para aplicação da estratégia recomendada. Em muitas empresas, os custos reais não são sistematicamente levantados pela falta de uma cultura de planejamento e de sistematização de informações. Dessa forma, muitas decisões são baseadas em estimativas e conhecimento tácito dos gestores (NICOLINI et al., 2000).

Outro aspecto relevante no contexto do setor de edificações é o baixo poder de influência exercido pelas empresas construtoras sobre os fornecedores de materiais e componentes. Apesar do poder de compra decorrente da produção em série de um número grande de unidades habitacionais, as empresas que atuaram na produção de EHIS pelo PAR nos estudos desenvolvidos por Simões, Gomes e Hirota (2007) e Gomes, Guadanhim e Hirota (2006) não estabeleciam articulações com fornecedores. Isso caracteriza uma barreira para o domínio dos custos de materiais e componentes, preconizado pela literatura, elemento fundamental para a estratégia Custeio-Meta no desenvolvimento do produto.

Além disso, a falta de informações consistentes sobre custos de produção e desempenho do produto também representa dificuldades para a utilização de técnicas como a Engenharia de Valor, as quais permitem estruturação dos custos baseada em funções a serem desempenhadas pelo produto para a avaliação do valor agregado e percebido pelo usuário, de que trata o terceiro princípio da aplicação do Custeio-Meta. Segundo esse princípio, a associação da criatividade da equipe de projeto e a formação de equipes multidisciplinares para análise dos custos do produto por função propiciam a análise integrada, de forma a possibilitar a agregação de valor ao produto.

\section{Avaliação contínua, pois o processo é cíclico, não linear}

Se de um lado as constantes avaliações e adequações são inerentes ao PAR, de outro há excesso de retrabalho. Por exemplo, quando o processo não é aprovado de imediato, todo ou parte dele deve ser refeito, o que representa acréscimo nos custos operacionais. São comuns as reclamações das empresas construtoras quanto à variação de critérios para aprovação das etapas de projeto junto aos departamentos dos órgãos públicos.

O tempo e os esforços empregados durante a fase de aprovação da proposta de novo empreendimento do PAR ao longo das (re)avaliações das etapas de projeto guarda certa similaridade com a exigência de constante avaliação do Custeio-Meta. Desse modo, há potencial para converter o que é visto como retrabalho em um processo constante e simultâneo de avaliação e aprimoramento das fases de concepção, a depender de adequações e integrações do fluxograma de projeto.

\section{Utilização combinada de técnicas como Engenharia de Valor, associadas à criatividade da equipe de projeto, à formação de equipes multidisciplinares e à estruturação dos custos baseada em funções, de modo a permitir a avaliação do valor agregado e percebido pelo usuário}

De modo geral, os sistemas estrutura, vedação e cobertura respondem por grande parte dos custos da edificação. A racionalização desses sistemas pode trazer resultados significativos, permitindo a aplicação de recursos em itens mais valorizados pelo usuário, mantendo a funcionalidade $\mathrm{e}$ 
agregando valor. O impacto no custo com equipe e tempo de projeto pode ser compensado com ganhos no custo de produção.

Um grande salto possível - e talvez o mais complexo - seria o credenciamento prévio dos fornecedores pelo gestor. Essa medida, ao qualificar fornecedores aptos a atender nacional ou regionalmente o Programa, traria o benefício da escala de produção. Se considerada a demanda nacional por HIS, haveria a possibilidade de desenvolvimento de produtos especificamente para atender às exigências do Programa. $\mathrm{O}$ desenvolvimento de produtos, em parceria entre projetistas, construtores e fornecedores, poderia realmente trazer ganhos em termos de qualidade e economia. Alterações dessa magnitude na cadeia produtiva esbarram nas características conservadoras há muito conhecidas no setor, mas que nos últimos anos têm recebido atenção e apresentam tendência de evolução.

\section{Envolvimento de toda a cadeia do PDP (investidores, projetistas, fornecedores, construtores, vendedores e clientes) com a formação de equipes multidisciplinares e implementação de peças e componentes modulares ou padronizados}

Poderiam ser apontadas inúmeras barreiras sob esse aspecto: as técnicas mais avançadas de construção e padronização de componentes são pouco usadas e a mão de obra carece de qualificação. Há grandes barreiras econômicas e culturais para a efetiva industrialização da construção civil no Brasil. Os programas e políticas governamentais nem sempre são eficientes ou mantém estabilidade de regras por longo prazo, o que dificulta o planejamento das empresas contratadas. A aferição e a garantia de qualidade do produto HIS carecem de confiabilidade.

Além disso, conforme Jacomit e Granja (2008), as indústrias de componentes e materiais para construção civil são muito maiores do que as construtoras, o que gera a situação inversa da desejada, ou seja, as construtoras, responsáveis pelo desenvolvimento e produção, precisam adequar-se à oferta de mercado, enquanto, numa aplicação efetiva de Custeio-Meta, os materiais e componentes deveriam ser desenvolvidos especificamente para determinada tipologia de EHIS, levando-se em conta principalmente a economia de escala. Pesa desfavoravelmente à ideia o fato de que o setor industrial é muito mais disciplinado do que a construção civil.

No entanto, uma agenda positiva e coordenada pelo Poder Público e seus gestores tem potencial para transformar o setor. É possível conjecturar algumas condições que poderiam ser atingidas em médio prazo, como, por exemplo, a integração dos fornecedores ao processo desde as fases préprojeto.

Componentes desenvolvidos especificamente para o programa teriam maior possibilidade de atingir o equilíbrio entre custo e benefício desejado pelo cliente final, alinhando a prática à teoria da estratégia Custeio-Meta. A criação de mecanismos institucionais que promovam convênios multidisciplinares e interorganizacionais poderia viabilizar o trabalho conjunto entre fornecedores, projetistas e construtores, num ambiente mais próximo ao que ocorre, por exemplo, na indústria automobilística, em que componentes são desenvolvidos sob a coordenação da empresa montadora levando em conta aspectos de qualidade e custo.

Uma postura que valoriza o processo de projeto e a fase de desenvolvimento do produto, embora demande mais tempo, tende a reduzir os custos e o tempo de execução. As construtoras credenciadas deveriam possuir certificações de qualidade e, em especial, de políticas de produção enxuta, fator fundamental para o domínio e o controle dos custos. $\mathrm{O}$ passo seguinte levaria à racionalização $\mathrm{e}$ industrialização, uma vez que a demanda por habitação é grande e está no centro das políticas públicas federais. Se considerada a demanda e a produção nacional, há mercado suficientemente amplo para a produção de componentes, processos e elementos construtivos em série, os quais poderiam ser utilizados em diversas soluções tipológicas, ${ }^{7}$ com grandes ganhos em escala.

Tais possibilidades, evidentemente, dependem de alterações importantes na indústria da construção civil, que possui características próprias, como, por exemplo, o conservadorismo. O combustível para a quebra de inércia pode ser justamente a gestão

\footnotetext{
7 Uma das grandes críticas quanto à qualidade da habitação de interesse social no Brasil reside na excessiva repetição de unidades e edifícios padronizados. A ideia básica defendida neste trabalho não implica necessariamente essa situação. A valorização das etapas iniciais de projeto e a formação de equipes competentes, aliada à industrialização, ao contrário, podem permitir a melhoria da qualidade arquitetônica e espacial, através da busca por características que promovam a diversidade. Acerca da qualidade da habitação coletiva, "Alexander et al. (1977) $)^{8}$ distanciam-se dos métodos desenvolvidos a partir das condições construtivas e de produção em massa [...]. Muitos parâmetros projetuais criticam os sistemas estruturais determinados mais pelas necessidades do processo de produção do que por uma forma de lógica construtiva e dos usuários." (apud BARROS, 2008). Entre os parâmetros projetuais defendidos pelo autor estão a garantia de privacidade, a flexibilidade de uso e a possibilidade de expansão, fatores que indicam a importância da diversidade tipológica.

${ }^{8}$ ALEXANDER, C. et al. A Pattern Language: towns, buildings, construction. New York, NY: Oxford University Press, 1977.
} 
eficiente de custos, que traz como consequência desejável a certeza de lucratividade, motor principal para alavancar transformações.

Verifica-se, assim, que o PAR e, atualmente, o Programa Minha Casa, Minha Vida constituem-se num campo fértil para investigação, cujas bases possuem características favoráveis a mudanças necessárias à aplicação da teoria do Custeio-Meta e realmente oferecem oportunidades de grande melhoria na produção de habitação, malgrado as previsíveis dificuldades apontadas. Na sequência deste trabalho, analisa-se a etapa de pré-projeto do PDP do PAR e verifica-se a inserção de ações com base na teoria estudada, visando a um fluxograma de processo de projeto que contemple a abordagem Custeio-Meta.

\section{Processo de Projeto}

Como já demonstrado, a ênfase nas fases iniciais de concepção do produto justifica-se tanto por razões de previsão e domínio dos custos como de perspectivas de melhores soluções para os problemas de projeto. A fase inicial do PDP, definição de projeto, a qual é muitas vezes incerta e conjectural, só poderia ser iniciada a partir do estabelecimento do custo-meta, o qual depende do preço definitivo do produto no mercado e da margem de lucro, fatores estabelecidos previamente, conforme visto.

Uma grande diferença na abordagem Custeio-Meta com relação à prática comum quanto ao projeto reside no fato de que, após o desenvolvimento dos estudos preliminares, faz-se necessário um salto imediato para uma fase bem mais avançada, que contenha informações aprofundadas sobre materiais e componentes. Na realidade, os próprios estudos preliminares, por mais conceituais que sejam, não podem em nenhuma hipótese desconsiderar a variável custo. Esse material deve conter os elementos necessários ao levantamento dos custos reais de produção - próxima etapa no mapa. Para isso, verifica-se que, mesmo nessa fase inicial, o projeto deve ser extremamente esmiuçado, inclusive com especificações, o que, naturalmente, demanda tempo bem maior do que na prática atual, além de depender de quadros técnicos mais preparados e munidos de ferramentas tecnológicas de informação e gestão.

Como o objetivo é o domínio dos custos reais, não basta simplesmente estimar valores ou basear-se no preço de materiais e componentes disponíveis no mercado. Aqui se chega a um gargalo fundamental: a necessidade de envolvimento dos fornecedores e executores da obra. De um lado, sem a participação dos responsáveis pela execução fica impossível orçar serviços, cujos custos podem variar enormemente de uma empresa construtora para a outra, dependendo da gestão empregada. Por outro lado, o envolvimento dos fornecedores através da adoção de "livro-aberto" - é a única forma de emprego de componentes desenvolvidos especificamente para determinada demanda (NICOLINI et al., 2000).

Quando se trata da produção de HIS, deve-se levar em conta que há grande demanda, o que permite pensar em processos, elementos e componentes desenvolvidos pela indústria especificamente para atender às exigências do programa em questão, levando em conta desde o menor elemento até as expectativas do público-alvo, permitindo, através da intercambialidade e modularidade, a produção de habitação coletiva de diferentes tipologias. A combinação variada de elementos construtivos diversos contribuiria para o incremento da qualidade espacial e arquitetônica, evitando as simples repetições de unidades-padrão ou blocospadrão.

O resultado do levantamento de custos poderia ser chamado de pré-orçamento, no sentido de que, apesar do alto grau de precisão, ainda é provisório, pois provavelmente a soma do custo de produção obtido com os lucros estimados no início superará o preço de mercado estabelecido.

O último passo coincide com a descoberta de soluções alternativas para produzir um projeto que proporcione aumento de valor. Esse passo pode requerer muita criatividade por parte dos projetistas com contribuições da equipe envolvida. Novamente verifica-se a necessidade de tempo e investimento na fase de projeto, para que, dispondo das informações de custo real da solução anterior e de que "frentes" atacar, se faça novo estudo. É preciso levar em conta que, apesar de não partir do zero, é um trabalho complexo, de ajustes finos e dependentes da integração da equipe completa de projeto, executores e fornecedores. Para atingir os objetivos é preciso, então, lançar mão de ferramentas de Engenharia de Valor. As novas decisões de projeto serão, portanto, baseadas não apenas na substituição de materiais e componentes ou adoção de tecnologias diversas, mas poderá, inclusive, exigir revisões de caráter conceitual, o que naturalmente demandará o reinício do processo. A chave para o sucesso nessa fase é o profundo conhecimento do produto em desenvolvimento e a capacidade de decompôlo em partes passíveis de receber atributos de valor. A literatura disponível indica a segmentação com base na funcionalidade, o que se torna uma tarefa complexa quando aplicada a edificações, particularmente residenciais. 
Observa-se, assim, que o ciclo se encerrará no momento em que o custo-meta previamente estabelecido for atingido, garantindo a qualidade $\mathrm{e}$ a funcionalidade do produto.

Desse modo, pode-se concluir que a fase de projeto, permeada pelo uso de ferramentas de Engenharia de Valor, se estende por um tempo considerável na cadeia. Tal fato implica a quebra de importantes paradigmas:

(a) maior valorização do projeto, o que significa mais tempo de dedicação e mais recursos;

(b) o estabelecimento do custo-meta e o desenvolvimento dos projetos só se concretiza na hipótese da formação prévia da equipe - que deve incluir executores e fornecedores;

(c) a produção pública de HIS, em geral regida pela Lei 8.666/1993 (BRASIL, 1993), esbarra na necessidade de determinação prévia de todos os agentes, mesmo que o objeto final não esteja definido; e

(d) programas públicos do tipo PAR e Minha Casa, Minha Vida possuem características mais favoráveis à aplicação da estratégia, pois dependem do envolvimento das construtoras desde o início do projeto, inclusive como motivadoras do processo.

Como visto anteriormente, Ballard (2006) defende uma reformulação no modo de conduzir as fases iniciais do PDP, uma vez que, na construção civil, o trabalho é feito superficialmente. Pode-se dizer que a retroalimentação das informações necessárias ao processo de projeto deve partir dos vários agentes no momento da formulação do problema, ou seja, no levantamento de todos os requisitos de projeto e estabelecimento do preçometa do produto, bem como das possíveis alternativas para tipologia, tecnologia e dimensionamento. Dessa forma, os processos que contemplam definição de políticas, diretrizes, alocação de recursos, identificação e caracterização da demanda e levantamento de condicionantes já devem ser contemplados desde os primeiros estudos.

$\mathrm{Na}$ construção civil o método para equilibrar a satisfação esperada do usuário e os custos ainda está para ser consolidado, mas parece claro que algumas etapas são imprescindíveis:

(a) levantamento das expectativas do usuário final;

(b) Engenharia de Valor, identificando elementos passíveis de, por um lado, simplificação ou eliminação e, de outro, de incremento de qualidade; e (c) retroalimentação da equipe de projeto, mediante o cruzamento das informações de custo obtidas no cenário descrito acima com a expectativa do usuário, objetivando a otimização das características mais valorizadas pelo usuário final.

As fases iniciais do PDP constituem o momento em que o custo-alvo deve ser determinado e no qual já deve haver a participação plena da equipe multidisciplinar, a qual deve considerar os objetivos do cliente ou empreendedor, os meios para atingi-los e as limitações ou condicionantes (BALLARD, 2006).

A menos que o processo de tomada de decisão seja mudado do papel do arquiteto para o da equipe de projeto, este eficiente processo de planejamento de custos permanecerá meramente de interesse acadêmico. (LANGSTON, $2002^{9}$ apud BALLARD, 2006, p. 78)

Porém, simplesmente agregar novos atores não trará automaticamente bons resultados. Os papéis e responsabilidades devem ser reaprendidos, pois profissionais invadirão o território uns dos outros, e isso pode gerar conflitos. É necessária uma nova mentalidade organizacional.

Comparando o modelo conceitual de Ballard (2006) para o Lean Project Delivery System com o diagrama conceitual do PDP do PAR e seus agentes apresentado por Gomes, Guadanhim e Hirota (2006) (Figura 4), verifica-se que, no caso do PAR, na fase de pré-projeto já ocorre a efetiva participação de grande parte dos agentes envolvidos: Ministério das Cidades, Caixa Econômica Federal, companhias de habitação e o Poder Público local, os quais estabelecem as diretrizes a serem adotadas para o desenvolvimento do produto. Essa fase é caracterizada pela formulação do "problema" a ser solucionado pelo projeto. São estabelecidas as relações formais entre os participantes, como convênios, credenciamento de profissionais e empresas, é feita a contextualização do problema, são definidas as políticas e diretrizes, alocados recursos, identificados os clientes e caracterizada a demanda, bem como levantadas as condicionantes de projeto. Importante aspecto dessa fase do Programa é o estabelecimento do preço. A partir daí, iniciam-se os trabalhos efetivos de elenco e escolha de possíveis soluções para tipologia, tecnologia, dimensionamento, etc.

\footnotetext{
${ }^{9}$ LANGSTON, Craig. A New Era in Cost Planning. In: BEST, R.; DE VALENCE, G. Design and Construction: building in value. Oxford: Butterworth-Heinemann, 2002. p. 59-74.
} 


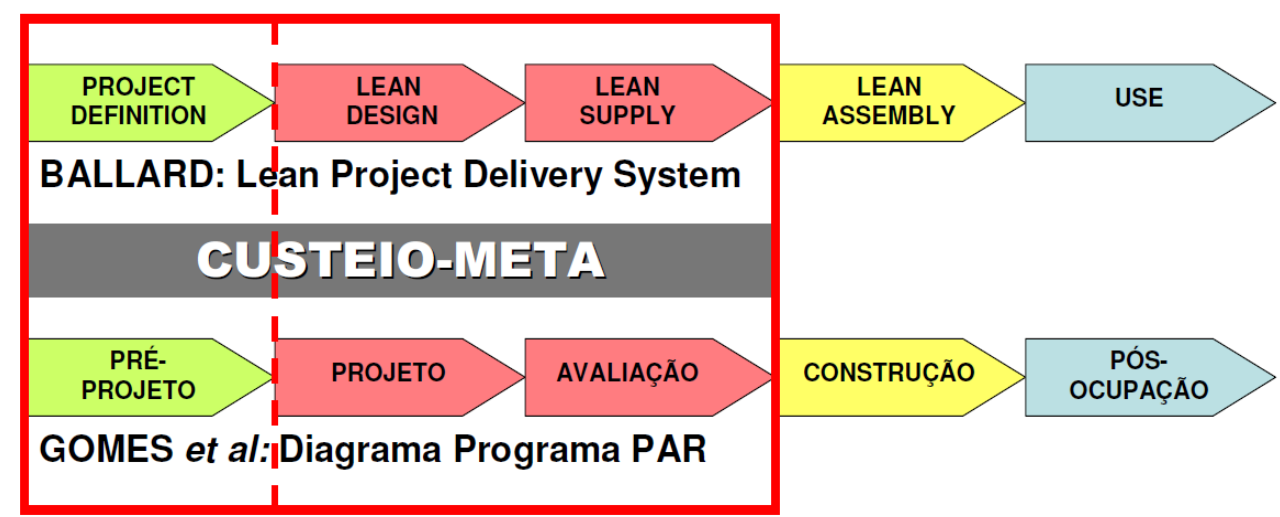

Figura 4 - Comparação entre modelo conceitual para o Lean Project Delivery System e diagrama conceitual do PAR

Fonte: Ballard (2006) e Gomes, Guadanhim e Hirtoa (2006).

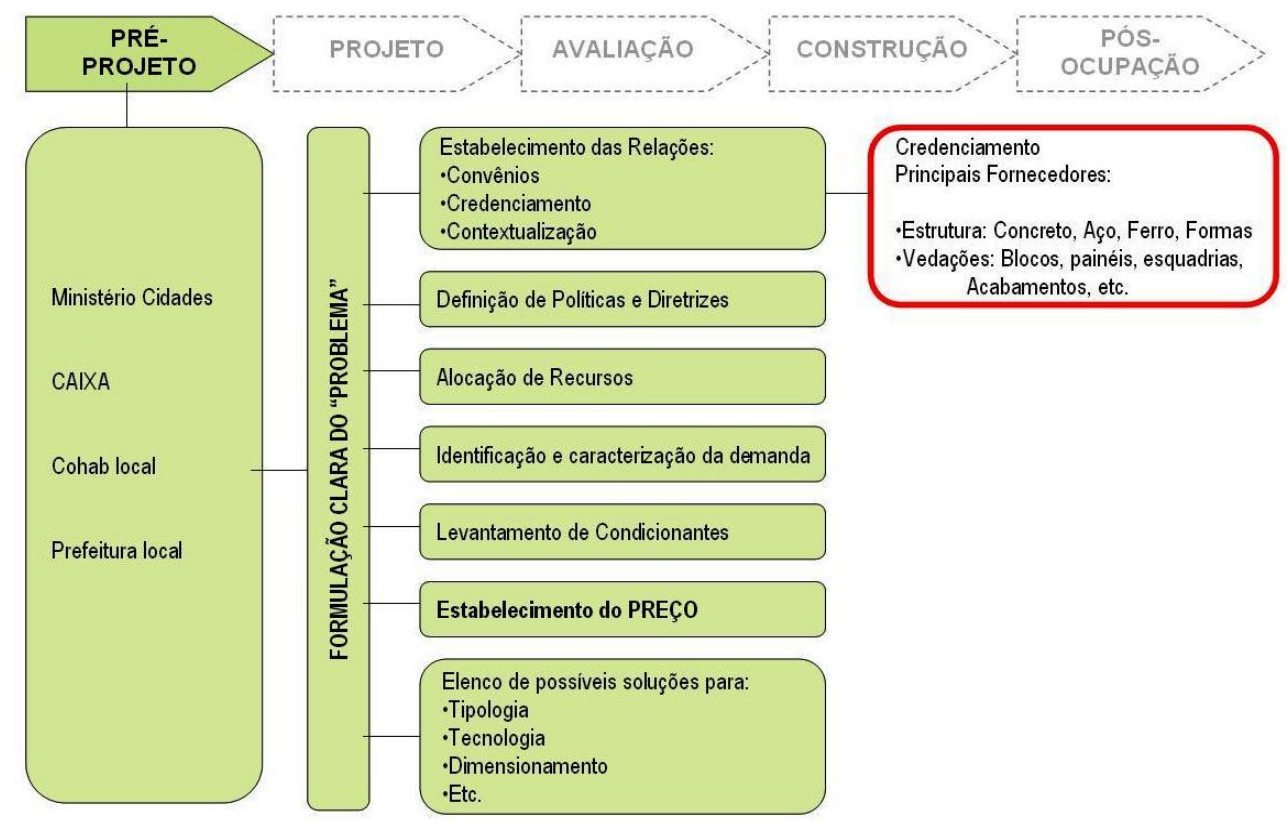

Figura 5 - Oportunidades de aplicação do Custeio-Meta na fase de pré-projeto do PAR

Observa-se aqui a falta de participação de um componente fundamental, segundo a estratégia de Custeio-Meta apresentada por Cooper e Slagmulder (1997): os fornecedores. Uma possível solução para isso seria o estabelecimento de convênios e credenciamento dos principais fornecedores, juntamente com as construtoras junto à fase de pré-projeto. Essa seria uma estratégia fundamental no processo de projeto. Fornecedores de subsistemas como estrutura (concreto, aço, fôrmas), vedações (blocos, painéis, esquadrias, acabamentos em geral, etc.) poderiam ser credenciados local ou nacionalmente e selecionados nessa fase. Esse credenciamento prévio traria inúmeros benefícios ao processo, pela possibilidade da proposição de soluções viáveis sob o ponto de vista de custo, qualidade e funcionalidade para tipologia, tecnologia e dimensionamento do produto. Sendo assim, há uma real oportunidade de aplicação da abordagem Custeio-Meta na etapa de pré-projeto, por meio do envolvimento dos principais agentes do programa PAR e do aumento da efetividade na gestão dos custos desde o início, como mostra a Figura 5.

Partindo para a fase de projeto, a inserção de ferramentas de Custeio-Meta promoveria a atuação das empresas construtoras e suas equipes multidisciplinares na realização do estudo de viabilidade do empreendimento, já contando com a contribuição fundamental dos fornecedores.

Considerando a enorme quantidade de unidades habitacionais construídas em todo o país, é possível vislumbrar um quadro no qual as 
indústrias de materiais e componentes para construção civil passem a desenvolver produtos específicos para as exigências do Programa, o que, além de aumentar a eficiência e a satisfação dos requisitos em questão, permitiria grandes ganhos quanto à redução de custos com a produção em larga escala. Haveria, igualmente, uma pressão muito maior sobre essas indústrias para que também elas se tornassem mais eficientes e competitivas. Além disso, esse poderia ser um caminho para que os passos fossem alargados na direção da racionalização da construção e até mesmo na efetiva industrialização, incluindo aí componentes de peso, como estruturas e vedações. A formação de uma política de open book, ou livro aberto, em que os ajustes em projeto e especificações estariam sujeitos ao alcance de metas de custo dos fornecedores de materiais, componentes e prestação de serviços, aproximaria a construção civil da indústria manufatureira.

Uma abordagem nesses termos faria com que custo de produção fosse conhecido com razoável confiabilidade já na elaboração de um projeto básico, com informações para um pré-orçamento, realizado dentro de parâmetros muito mais precisos, garantindo que a expectativa de lucro seja confirmada no final. Por meio da estratégia de Custeio-Meta, os custos de produção (levando-se em conta os fornecedores previamente credenciados) seriam calculados. Somente quando atendessem ao custo-meta previamente estabelecido, os projetos poderiam ser submetidos à análise do gestor (CAIXA).

Caso os custos de produção alcançassem valores maiores que o custo-meta, proceder-se-ia à aplicação de ferramentas de Engenharia de Valor, de forma a ajustar ou reformular os projetos para novo orçamento. Na Figura 6, pode-se demonstrar esse fluxo de atuação da abordagem Custeio-Meta na fase de projeto. Ballard (2006) defende a adoção de workshops como uma das principais ferramentas de apoio ao aprimoramento de projetos quando se deseja alcançar metas de custo sem prejudicar a qualidade dos produtos. Somente depois de aprovado o projeto básico pelo gestor, é que o projeto executivo seria desenvolvido, evitando retrabalho sem resultados ou, pior ainda, mudanças durante a fase de produção, algo relativamente comum no cenário atual.

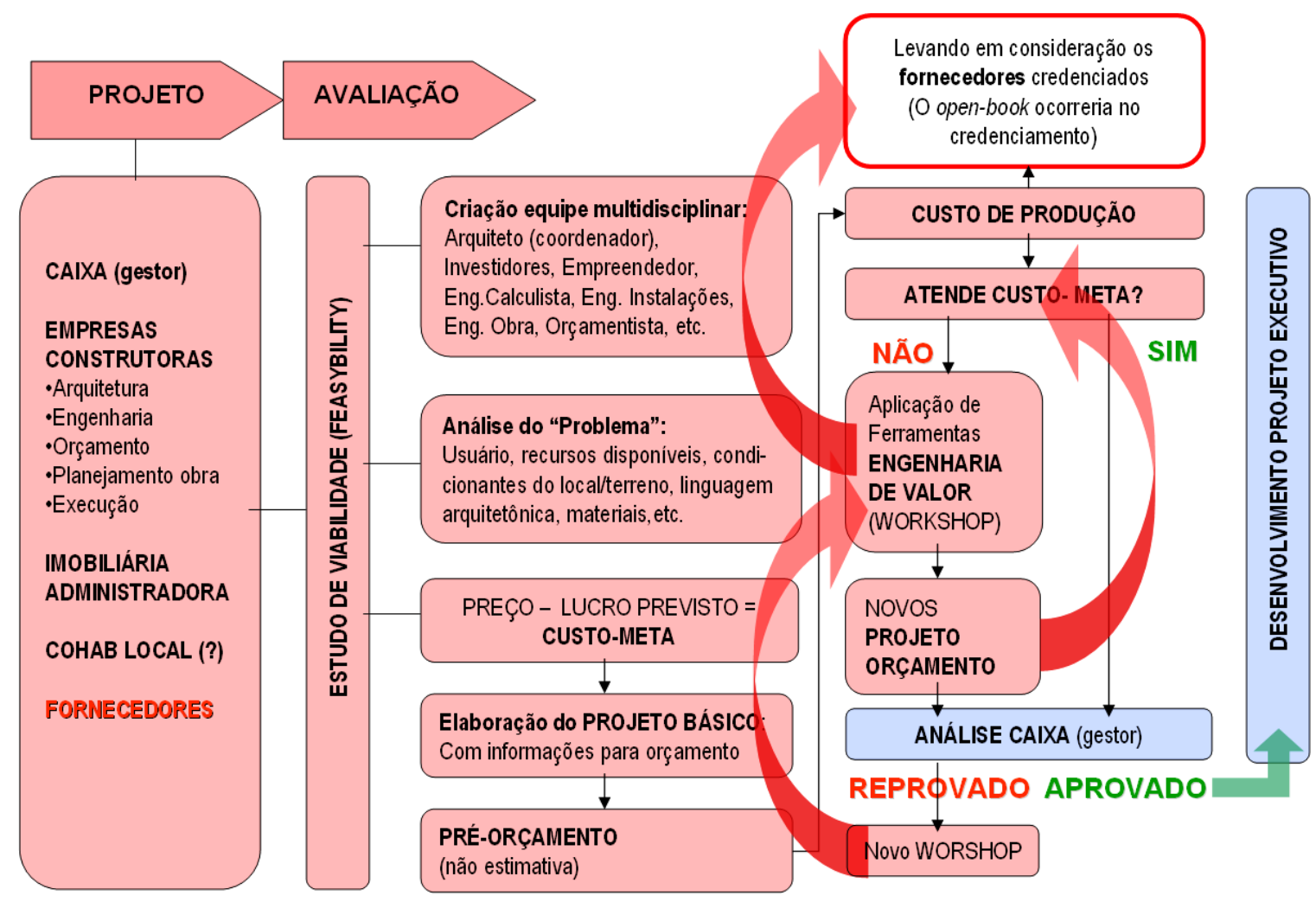

Figura 6 - Oportunidades de aplicação do Custeio-Meta na fase Projeto-Avaliação do PAR 


\section{Considerações finais}

Nos estudos realizados sobre o uso do CusteioMeta na construção civil (NICOLINI et al., 2000; BALLARD, 2006) não se observou a aplicação de todas as etapas e ferramentas do Custeio-Meta como demonstram os estudos na manufatura. Em especial a premissa do preço estabelecido pelo mercado não foi testada efetivamente e o envolvimento da cadeia de suprimentos ocorre parcialmente. O ambiente competitivo, definido pela participação das construtoras, não ocorre no nível da qualidade, mas nas concorrências públicas baseadas em menor preço. Nesse momento, os fornecedores ainda não foram escolhidos, um entrave para a implementação do Custeio-Meta. A atuação tardia da cadeia de suprimentos constituise numa barreira para a seleção de tecnologias e do estudo de tipologia. Os fornecedores de materiais de construção, especialmente no Brasil, em geral são organizações maiores do que as empresas construtoras, limitando a margem de negociação. Além disso, há dificuldades no desenvolvimento de análise do custo ao longo do ciclo de vida, devido à falta de informações.

Entretanto, é unânime que uma postura que valoriza o processo de projeto e as fases iniciais de desenvolvimento do produto, embora demande mais tempo, tende a reduzir os custos e o tempo de execução. Considerando que alguns programas efetivamente produzem EHIS em série, grande quantidade produzida regional ou nacionalmente poderia viabilizar a aplicação dos princípios do Custeio-Meta, através da racionalização da construção, aplicável na maioria dos casos.

\section{Referências}

AMARAL, D. C. et al. Gestão de Desenvolvimento de Produtos: uma referência para a melhoria do processo. São Paulo: Saraiva. 2006.

ANSARI, S. Value Engineering: management accounting, a strategic focus. 4. ed. New York: McGraw-Hill, 1997. 288 p.

BALLARD, G. Rethinking Project Definition in Terms of Target Costing. In: CONFERENCE OF THE INTERNATIONAL GROUP FOR LEAN CONSTRUCTION, 14., 2006, Santiago, Chile. Proceedings... Santiago: IGLC, 2006. p. 77-89.

BALLARD, G.; REISER, P. The St. Olaf College Fieldhouse Project: a case study in designing to target cost. In: CONFERENCE ON LEAN CONSTRUCTION, 12., 2004, Elsinore, Dinamarca. Proceedings... Elsinore, Dinamarca: 2004. 1 CD-ROM.
BARROS, Raquel R. M. P. Habitação Coletiva: a inclusão de conceitos humanizadores no processo de projeto. 2008. 189 f. Tese (Doutorado em Engenharia Civil) - Escola de Engenharia, Universidade Estadual de Campinas, Campinas, 2008.

BRASIL. Lei 8.666, 21 de junho de 1993. Diário Oficial da União, de 21 de junho de 1993.

COKINS, G. Integrating Target Costing and ABC. Journal of Cost Management, v. 16, n. 4, p. 1322, jul./ago. 2002.

COOPER, R.; SLAGMULDER, R. Target Costing and Value Engineering. Portland: Productivity Press, 1997. 379 p.

GAISER, B. German Cost Management Systems. Journal of Cost Management, Boston, v. 5, n. 11, p. 35-41, set./out. 1997.

GOMES, D. F. O.; GUADANHIM, S. J.; HIROTA, E. H. Diagnóstico da Gestão dos Requisitos de Clientes no Processo de Desenvolvimento do Produto de Empreendimentos de Habitação de Interesse Social em Londrina, PR. In: ENCONTRO NACIONAL DE TECNOLOGIA NO AMBIENTE CONSTRUÍDO, 11., 2006. Anais... São Paulo: ANTAC/UFSC, 2006. 8 p. CD-ROM.

GRANJA, A. D.; PICCHI, F. A.; ROBERT, G. Gestão de Custos na Construção Civil Sob um Enfoque de Processos: target costing e kaizen costing. In: SIMPÓSIO BRASILEIRO DE GESTÃO E ECONOMIA DA CONSTRUÇÃO, 4., 2005, Porto Alegre. Anais... Porto Alegre, 2005.

GRANJA, A. et al. O Custeio-Meta para o Desenvolvimento de Habitações de Interesse Social: diretrizes a partir da comparação de duas modalidades de provisão. Ambiente Construído, Porto Alegre, v. 11, n. 1, p. 53-66, jan./mar. 2011.

IBUSUKI, U.; KAMINSKI, P. C. Product Development Process With Focus on Value Engineering and Target-Costing: a case study in an automotive company. International Journal of Production Economics, v. 105, n.2, p. 459-474, 2007.

JACOMIT, A. M.; GRANJA, A. D. Diagnóstico de Pesquisas Sobre Target Costing (Custeio-Meta) na Construção Civil: lacunas de conhecimento e oportunidades de pesquisa. In: ENCONTRO NACIONAL DE TECNOLOGIA NO AMBIENTE CONSTRUÍDO, 12. 2008. Anais... São Paulo: ANTAC, 2008. 12 p. 1 CD-ROM.

LIMMER, C. V. Planejamento, Orçamentação e Controle de Projetos e Obras. Rio de Janeiro: LTC, 1997. 
MASCARÓ, J. L. O Custo das Decisões

Arquitetônicas. 3. ed. Porto Alegre: JLM, 2004.

MELHADO, S. B. O Processo de Projeto no

Contexto da Busca de Competitividade. In:

SEMINÁRIO INTERNACIONAL GESTÃO E

TECNOLOGIA NA PRODUÇÃO DE

EDIFÍCIOS, 1., São Paulo, 1997. Anais... São

Paulo: EPUSP, 1997. p. 7-51.

MIRON, L. I. G.; FORMOSO, C. T. . Client Requirement Management in Building Projects. In: CONFERECE ON THE INTERNATIONAL GROUP FOR LEAN CONSTRUCTION, 11., 2003, Blacksburg. Proceedings... Blacksburg : IGLC, 2003. p. 144-157.

MONDEN, Y. Sistemas de Redução de Custos: custo-alvo e custo kaizen. Tradução de Eduardo D' Agord Schaan. Porto Alegre: Bookman, 1999.

NICOLINI, D. et al. Can Target Costing and Whole Life Costing Be Applied in the Construction Industry? Evidence From Two Case Studies. British Journal of Management, London, v. 11, n. 4, p. 303-324, dez. 2000.

REIS, T.; PICCHI, F. A. Aplicação da "Mentalidade Enxuta" ao Fluxo de Negócios na Construção Civil. In: SIMPÓSIO BRASILEIRO DE GESTÃO E ECONOMIA DA CONSTRUÇÃO, 3., 2003, São Carlos. Anais... São Carlos: ANTAC/UFScar, 2003.
ROBERT, G. R.; GRANJA, A. D. Engenharia de Valor na Concepção de Unidades Comerciais de Varejo. In: ENCONTRO NACIONAL DE TECNOLOGIA NO AMBIENTE CONSTRUÍDO, 11. 2006. Anais... São Paulo: ANTAC/UFSC, 2006. 11 p. 1 CD-ROM.

SAKURAI, M. Target Costing and How to Use It. Journal of Cost Management, Boston, v. 3, n. 2, p. 39-50, Summer 1989.

SIMÕES, E.; GOMES, D. F. O.; HIROTA, E. H. Análise dos Processos de Negócios no Desenvolvimento Habitacional de Interesse Social do Programa PAR. Relatório Parcial de Pesquisa. Londrina: Universidade Estadual de Londrina, Departamento de Construção, 2007.

YU-LEE, R. T. Target Costing: what you see is not you get. Journal of Cost Management, Boston, v. 16, n. 4, p. 23-28, jul./ago. 2002.

\section{Agradecimentos}

Os autores agradecem ao Programa Habitare/FINEP, pelo apoio financeiro.

Revista Ambiente Construído

Associação Nacional de Tecnologia do Ambiente Construído

Av. Osvaldo Aranha, $99-3^{\circ}$ andar, Centro

Porto Alegre - RS - Brasil CEP $90035-190$

Telefone: +55 (51) 3308-4084

Fax: +55 (51) 3308-4054

www.seer.ufrgs.br/ambienteconstruido

E-mail: ambienteconstruido@ufrgs.br 